Yasutomo Shinohara $\cdot$ Yoichi Ezura $\cdot$ Hironori Iwasaki

Ichirou Nakazawa $\cdot$ Ryouta Ishida $\cdot$ Mina Kodaira

Mitsuko Kajita $\cdot$ Tadayoshi Shiba $\cdot$ Mitsuru Emi

\title{
Linkage disequilibrium and haplotype analysis among ten single-nucleotide polymorphisms of interleukin 11 identified by sequencing of the gene
}

Received: March 23, 2001 / Accepted: May 2, 2001

\begin{abstract}
Interleukin 11 (IL11) is a member of the interleukin 6 (IL6)-related cytokine subfamily, which stimulates $\mathrm{T}$ cell-dependent development of immunoglobulinproducing B cells. IL11 is also an important paracrine regulator of bone metabolism that induces formation of osteoclasts. In the work reported here, we sequenced the entire IL11 structural gene of 48 alleles in a Japanese test population. These experiments identified ten singlenucleotide polymorphisms (SNPs) and determined their allelic frequencies. One polymorphism was identified upstream of exon 1 , one in exon 3 , four in intron 4 and four in the $3^{\prime}$ untranslated region ( $\left.3^{\prime} \mathrm{UTR}\right)$ of exon 5 . Based on the genotype data, we constructed six haplotypes in the tested population. Two-way comparisons of SNPs revealed two combinations in complete linkage disequilibrium, one with SNPs at nucleotide positions $2753,3644,5154$, and 5568, and another with SNPs at positions 3686, 5141, and 5734. These results will be useful in disease-association studies where a contribution of the human IL11 gene has been suspected, especially in disorders affecting immune response and bone metabolism.
\end{abstract}

Key words Single-nucleotide polymorphism • Japanese population - Direct sequencing - Cytokine - Inflammation · Bone metabolism · Linkage disequilibrium

Y. Shinohara $\cdot$ Y. Ezura $\cdot$ H. Iwasaki $\cdot$ I. Nakazawa $\cdot$ R. Ishida $\cdot$

M. Kodaira $\cdot$ M. Kajita $\cdot$ M. Emi $(\bowtie)$

Department of Molecular Biology, Institute of Gerontology, Nippon Medical School, 1-396 Kosugi-cho, Nakahara-ku, Kawasaki 211-8533, Japan

Tel. +81-44-733-5230; Fax +81-44-733-5192

e-mail:memi@nms.ac.jp

Y. Shinohara $\cdot$ T. Shiba

Department of Molecular Biology, Kitasato University, Sagamihara, Japan

\section{Introduction}

Interleukin 11 is a member of the interleukin 6 (IL6)related cytokine subfamily that includes IL6, oncostatin M, leukemia inhibitory factor (LIF), and cardiotrophin 1 (Girasole et al. 1994). Single-nucleotide polymorphisms (SNPs) have emerged as valuable new tools to uncover the relationships between the contemporary organization of the human genome and disease susceptibility. In particular, their use in both genome-wide and gene-based association studies holds great promise for the identification of genes and gene variation involved in predisposition to complex disorders.

We sequenced the entire genomic sequence in DNA from 24 Japanese individuals (48 alleles), and identified ten SNPs at the IL11 locus and analyzed haplotypes and allelic frequencies. We also looked for linkage disequilibrium among the SNPs, in the hope of explaining the genetic diversity we found at this locus in our test population.

\section{Materials and methods}

DNA extraction. Blood samples were obtained with informed consent from 24 healthy Japanese individuals. Genomic DNA was prepared from each sample according to procedures described previously (Ikegawa et al. 1999).

PCR condition and primer design. PCR and sequencing primers were determined by analyzing the genomic sequence with DNAsis 3.0 software (Hitachi Software Engineering, Yokohama, Japan). The sequence numbering was adjusted to the RNA transcription start site (A at the top of GenBank M81890.1 is now +1). Polymerase chain reaction (PCR) primers were chosen at approximately $500 \mathrm{bp}$ intervals, with approximately $100 \mathrm{bp}$ overlap. PCR was performed as described previously (Tsukamoto et al. 1998). PCR amplification was performed under the following conditions: $94^{\circ} \mathrm{C}$ for $3 \mathrm{~min}, 72^{\circ} \mathrm{C}$ for $3 \mathrm{~min}$, then 5 cycles of $94^{\circ} \mathrm{C}$ 
for $30 \mathrm{~s}, 60^{\circ} \mathrm{C}$ for $30 \mathrm{~s}, 72^{\circ} \mathrm{C}$ for $30 \mathrm{~s}$, and 25 cycles of $94^{\circ} \mathrm{C}$ for $30 \mathrm{~s}, 58^{\circ} \mathrm{C}$ for $30 \mathrm{~s}, 72^{\circ} \mathrm{C}$ for $30 \mathrm{~s}$.

DNA sequencing. Following purification by affinity membrane, PCR products were subjected to cycle sequencing with the indicated primer as described previously (Tsukamoto and Emi 1998). Sequence differences in the 24 samples were regarded as SNPs.

Determination of haplotype frequencies and tests of linkage disequilibrium. Haplotype frequencies among the 100 alleles investigated were calculated by Arlequin software (Genetics and Biometry Laboratory, Geneva, Switzerland). We tested for linkage disequilibrium of all possible twoway combinations of the novel SNPs and the Alu I/D polymorphism using several widely used methods $\left(D, D^{\prime}\right.$, and $r^{2}$, Lewontin 1988; Miller et al. 2000).

\section{Results and discussion}

A total of 24 Japanese individuals were genotyped to identify sequence variations in all five exons and surrounding regions of the IL11 structural gene, $6870 \mathrm{bp}$ in length. A total of ten SNPs were found. Locations of those SNPs are shown in Fig. 1 in relation to the genomic structure of the IL11 gene. Among the ten SNPs found, one was located upstream from the first exon, i.e., a G/A substitution at nucleotide (nt) position -518 . One was located in exon 3, i.e., $\mathrm{A} / \mathrm{G}$ at nt 1937 . Four were located in exon 5, i.e., A/G at nt 5143, C/G at nt 5154, G/A at nt 5568, and T/C at nt 5734. The other four SNPs were found in the fourth intron, i.e., C/ $\mathrm{T}$ at nt 2267, C/T at nt 2753, G/A at nt 3644, and T/C at nt
Fig. 1. Relationship between genomic structure and the location of single-nucleotide polymorphisms (SNPs) in the human interleukin 11 (IL11) gene
$\operatorname{IL11}$

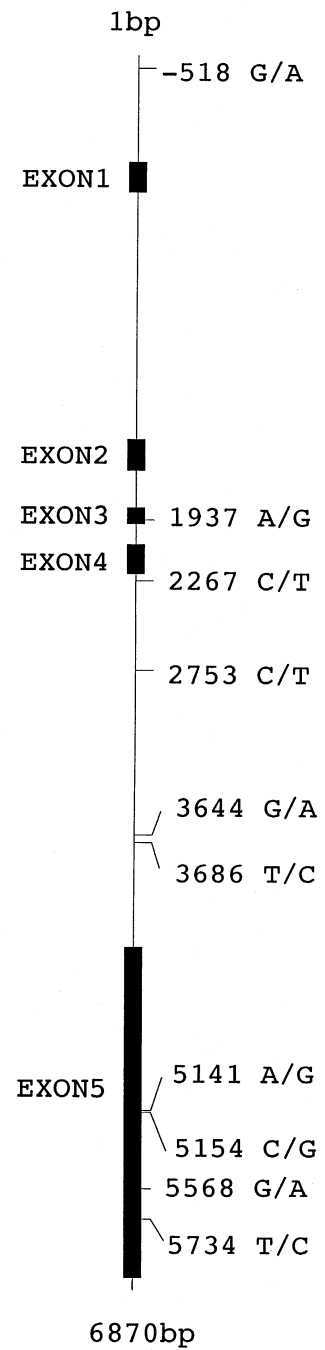

Table 1. Polymorphisms in the human $I L 11$ gene in the Japanese population

\begin{tabular}{|c|c|c|c|}
\hline Region & Position & Nomenclature & Frequency \\
\hline 5'upstream & -518 & $-518 \mathrm{G} / \mathrm{A}$ & $\mathrm{G}(0.73), \mathrm{A}(0.27)$ \\
\hline exon3 & 1937 (A82A) & $1937 \mathrm{~A} / \mathrm{G}$ & $\mathrm{A}(0.74), \mathrm{G}(0.26)$ \\
\hline intron4 & 2267 (IVS4+36) & $2267 \mathrm{C} / \mathrm{T}$ & $\mathrm{C}(0.98), \mathrm{T}(0.02)$ \\
\hline intron4 & 2753 (IVS4+622) & $2753 \mathrm{C} / \mathrm{T}$ & $\mathrm{C}(0.85), \mathrm{T}(0.15)$ \\
\hline intron4 & 3644 (IVS4-619) & $3644 \mathrm{G} / \mathrm{A}$ & $\mathrm{G}(0.83), \mathrm{A}(0.17)$ \\
\hline intron4 & 3686 (IVS4-577) & $3686 \mathrm{~T} / \mathrm{C}$ & $\mathrm{T}(0.90), \mathrm{C}(0.10)$ \\
\hline 3'UTR & $5141\left(3^{\prime} \mathrm{UTR}+708\right)$ & $5141 \mathrm{~A} / \mathrm{G}$ & $\mathrm{A}(0.90), \mathrm{G}(0.10)$ \\
\hline $3^{\prime} \mathrm{UTR}$ & $5154\left(3^{\prime} \mathrm{UTR}+721\right)$ & $5154 \mathrm{C} / \mathrm{G}$ & $\mathrm{C}(0.85), \mathrm{G}(0.15)$ \\
\hline $3^{\prime} \mathrm{UTR}$ & $5568\left(3^{\prime} \mathrm{UTR}+1135\right)$ & $5568 \mathrm{G} / \mathrm{A}$ & $\mathrm{G}(0.85), \mathrm{A}(0.15)$ \\
\hline $3^{\prime} \mathrm{UTR}$ & $5734\left(3^{\prime} \mathrm{UTR}+1301\right)$ & $5734 \mathrm{~T} / \mathrm{C}$ & $\mathrm{T}(0.90), \mathrm{C}(0.10)$ \\
\hline
\end{tabular}

UTR, untranslated region

Table 2. Frequencies of haplotypes constructed from nine SNPs

\begin{tabular}{lllllllllll}
\hline No. & frequency & -518 & 1937 & 2753 & 3644 & 3686 & 5141 & 5154 & 5565 & 5734 \\
\hline 1 & 0.0227 & A & A & C & G & T & A & C & G & T \\
2 & 0.1136 & A & G & C & G & C & G & C & G & C \\
3 & 0.0234 & A & G & C & G & T & A & C & G & T \\
4 & 0.1130 & A & G & T & A & T & A & G & A & T \\
5 & 0.7039 & G & A & C & G & T & A & C & G & T \\
6 & 0.0234 & G & A & T & A & T & A & G & A & T
\end{tabular}

SNP at position 2267 was excluded because of low frequencies of the minor alleles 


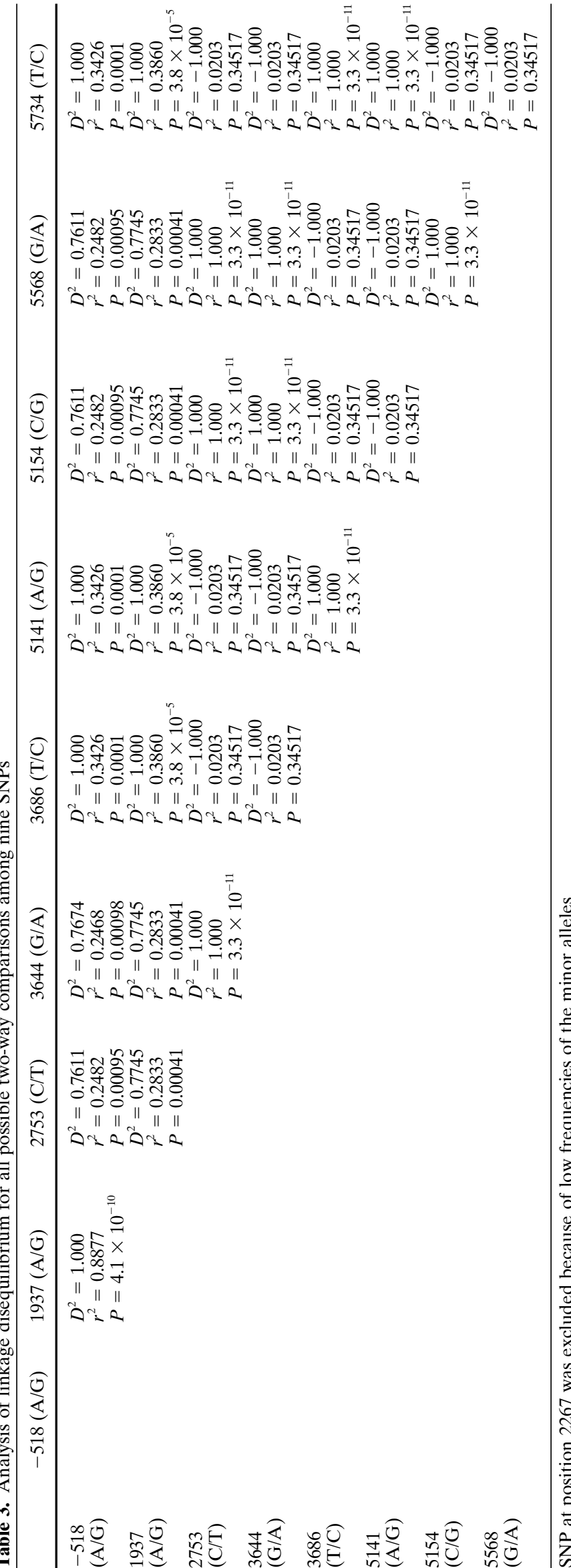

3686. Table 1 summarizes the allele frequencies of the novel SNPs determined in the 24 Japanese individuals, a total of 48 alleles. SNPs at positions 1937 (A/G) and $5568(\mathrm{G} / \mathrm{A})$ are reported in the Japanese population in the Institute of Medical Science-Japan Science and Technology Corporation (IMS-JST) SNP database (http://snp.ims.u-tokyo.ac.jp/ index.html). None of the ten SNPs we found were reported in the U.S. National Center for Biotechnology Information (NCBI) dbSNP database (http://www.ncbi.nlm.nih.gov/ SNP/index.html).

Haplotype frequencies among the 48 alleles investigated were calculated by Arlequin software (Genetics and Biometry Laboratory). The results are summarized in Table 2. The SNPs at position 2267 were excluded from this analysis because their minor alleles were too rare. Nevertheless, we identified six distinct haplotypes among the 24 Japanese subjects, one of which accounted for $70 \%$ of all haplotypes. We tested for linkage disequilibrium of all possible two-way combinations of the SNPs using several widely used methods ( $D, D^{\prime}$, and $r^{2}$; Lewontin 1988; Miller et al. 2000). Significance levels were determined by $\chi^{2}$ statistics for the corresponding $2 \times 2$ table. Results are shown in Table 3 . Again, the SNP with rare alleles (at position 2267) was excluded from the analysis. Two combinations in complete linkage disequilibrium were found, one with SNPs at positions $2753,3644,5154$ and 5568 and another with SNPs at positions 3686, 5141, and 5734 .

Interleukin 11 is a member of the interleukin 6 (IL6)related cytokine subfamily. Its immunological function is to stimulate $\mathrm{T}$ cell-dependent development of immunoglobulin-producing B cells and to collaborate with IL3 in supporting murine megakaryocyte colony formation. IL11 is an important osteoblast-derived paracrine regulator of bone metabolism and induces the formation of osteoclasts. Osteoclasts formed in the presence of IL11 are capable of bone resorption (Girasole et al. 1994). These data suggest that ILI1 is a candidate gene involved in osteoclast differentiation and thus in regulation of bone mineral density in human physiology and pathology.

In conclusion, these ten polymorphisms, their haplotypes, and state of linkage disequilibrium will be useful for investigation of a possible relationship between genetic variation at the human IL11 locus and human diseases, especially in association studies between specific polymorphisms and susceptibility to inflammatory diseases and osteoporosis.

Acknowledgments This work was supported in part by a special grant for strategic advanced research on cancer and genome science from the Ministry of Education, Science, Sports and Culture of Japan; by a research grant from the Ministry of Health and Welfare of Japan; and by a Research for the Future program grant of the Japan Society for the Promotion of Science.

\section{References}

Girasole G, Passeri G, Jilka RL, Manolagas SC (1994) Interleukin 11: a new cytokine critical for osteoclast development. J Clin Invest 93:1516-1524 
Ikegawa S, Isomura M, Koshizuka Y, Nakamura Y (1999) Cloning and characterization of human and mouse PROSC (proline synthetase co-transcribed) genes. J Hum Genet 44:337-342

Lewontin RC (1988) On measures of gametic disequilibrium. Genetics 120:849-852

Miller PT, Sardina IB, Saccone NL, Putzel J, Laitinen T, Cao A, Kere J, Pilia G, Rice JP, Kwok PY (2000) Juxtaposed regions of extensive and minimal linkage disequilibrium in human Xq25 and Xq28. Nat Genet 25:324-328

Tsukamoto K, Emi M (1998) A polymorphic CA repeat sequence at the human calcitonin locus. J Hum Genet 43:146-147

Tsukamoto K, Haruta K, Shiba T, Emi M (1998) Isolation and mapping of a polymorphic CA repeat sequence at the human interleukin 6 locus. J Hum Genet 43:71-72 